\title{
Electrical Optimization of the ICH Antenna Array for ITER*
}

\author{
P. M. Ryan, D. W. Swain, M. D. Carter, D. J. Taylor, G. Bosia $†$ \\ Oak Ridge National Laboratory, Oak Ridge, TN,37831-8071, \\ TITER Joint Central Team, Garching, Germany
}

\begin{abstract}
The present design of the ITER ICH antenna array comprises two poloidal by four toroidal current elements in each of four ports. Each current element forms a resonant double loop (RDL) with power fed to a pretuned matchpoint on the strap; the matching is accomplished using slow-wave transmission lines as adjustable shorted-stub tuners on either end of the current strap. The power requirement is $12.5 \mathrm{MW}$ per port over the frequency range of $40-70 \mathrm{MHz}$, with extended operation to $80 \mathrm{MHz}$ desirable. The antenna design optimization process includes (1) strap shaping to minimize strap voltages and rf E-fields along B-field lines and (2) frame/Faraday shield geometry design to improve plasma coupling, wave spectrum directivity, and phase control. For the ignited plasma parameters, the optimized array design delivers full power over the ranges of 40-80 $\mathrm{MHz}$ in frequency and $0^{\circ}$ to $180^{\circ}$ in phase. The maximum strap voltage is $41 \mathrm{kV}$ and the maximum parallel E-field is $16 \mathrm{kV} / \mathrm{cm}$ for the worst case over these ranges. The array directivity for current drive operation is calculated to be close to $80 \%$.
\end{abstract}

\section{INTRODUCTION}

The reference geometry, shown in Fig. 1, upon which this optimization study is based is the $4 \times 2$, in-port antenna array presented at the Joint ITER JWM/CCFW Meeting in Garching ${ }^{1}$. The design criteria are to deliver plasma heating power of $12.5 \mathrm{MW} /$ port, over a frequency range of $40-80 \mathrm{MHz}$, to a plasma whose nominal surface is positioned on the order of $15 \mathrm{~cm}$ from the first wall. The essence of the optimization exercise is to minimize the voltages and electric fields occurring on the antenna structure while still providing acceptable mechanical strength, sufficient array directivity for good current drive efficiency, and a stable, controllable electrical component for the power delivery system.

The reference design was extensively analyzed with both a two-dimensional (2-D) Laplace $\operatorname{code}^{2}$ and a three-dimensional (3-D) electromagnetic code (ARGUS) ${ }^{3}$, and its electrical characteristics were determined. Changes in these electrical characteristics with system geometry changes were then studied with the 2-D Laplace code. The parameters of interest are the strap inductance and capacitance (alternatively, the strap impedance and wave propagation velocity), and the mutual inductance between neighboring straps. The plasma loading resistance was determined by RANT3D 4 , a 3-D cold-plasma coupling code.

Using these parameters, a lossy transmission model yielded the maximum strap voltage for full power delivered to the plasma, as a function of frequency and phase as the strap dimensions and septa positions were varied. The maximum electric fields, parallel and perpendicular to the magnetic field lines, were also calculated by the 2-D Laplace code.

*Oak Ridge National Laboratory, managed by Lockheed Martin Energy Research Corp. for the U.S. Department of Energy under contract number DE-AC05-96OR22464. 


\section{ELECTRICAL ANALYSIS}

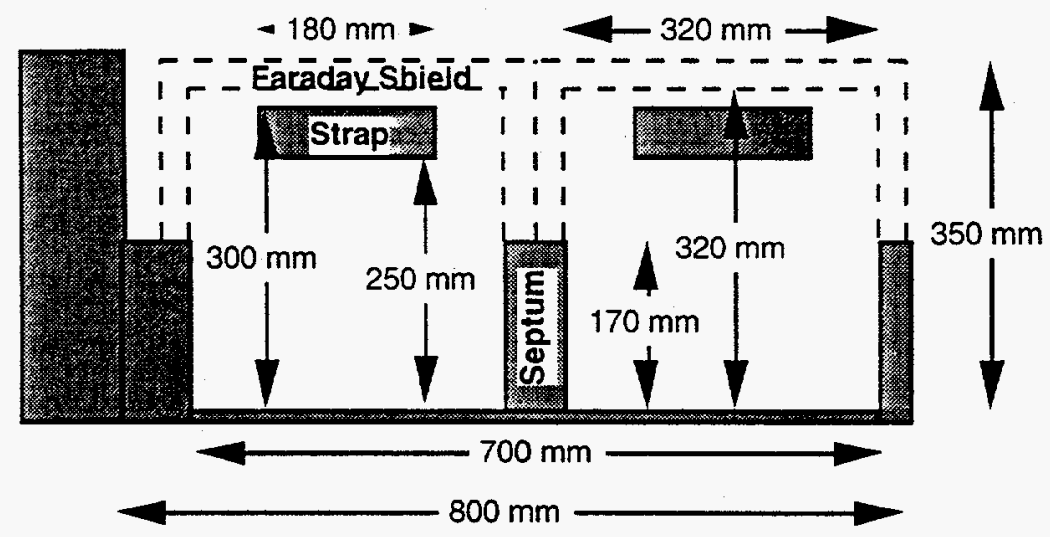

Fig. 1. Nominal dimensions of antenna geometry. Only two (outer and inner) of four straps in toroidal direction are shown (toroidal symmetry assumed).

The electrical analysis proceded in stages, each stage simplifying the analysis to provide for more rapid calculations and more detailed strap geometry. The first stage modeled the full four-strap reference design with Faraday shield slanted at an angle of $17.4^{\circ}$ with respect to the horizontal, using the ARGUS code. The slanted shields gave strap impedances that were $1.5 \%$ lower than horizontal shields. The next stage compared the ARGUS results for horizontal shields with 2-D Laplace calculations for a four-strap array, as shown in Table 1. The next stage replaced the four-strap array with a single-strap representing an infinite array; the inductance of this "inner" strap increased from $2.72 \times 10^{-7} \mathrm{H} / \mathrm{m}$ to $2.86 \times 10^{-7} \mathrm{H} / \mathrm{m}$, while the coupling coefficient decreased from $14.4 \%$ to $13.9 \%$. The trend of these simplifying steps is to increase the strap inductance slightly, thus overestimating the voltage for a given power. The final stage of analysis used rounded ends on the straps, with the radius of curvature equal to half the strap thickness. The 2D Laplace code was used to calculate the inductance and capacitance per unit length ( $\mathrm{L}^{\prime}$ and $\mathrm{C}^{\prime}$ ) and the mutual coupling coefficient $(\mathrm{k})$. Figs. 2 and 3 show the perpendicular and parallel electric field contours for an 18 $\mathrm{cm}$ wide, $5 \mathrm{~cm}$ thick current strap with a $2 \mathrm{~cm}$ gap to the Faraday shield.

\section{PLASMA LOADING CALCULATIONS}

Fig. 4 demonstrates the strong dependance of loading on the gap between the antenna and separatrix, particularly for the larger phase angles. Fig. 5 shows the decrease in loading as the relative phase angle increases. due to the shift of the spectral peaks to higher values of $n_{\|}$. The plasma loading is relatively insensitive to the strap width and the septum position, as is the array directivity. The directivity at $\theta=\pi / 2$ only decreases from 0.83 to 0.78 as the solid septa are moved from 19 to $11 \mathrm{~cm}$ from the first wall. This is more than compensated by the decrease in strap impedance and mutual coupling, and the increased mechanical strength of the Faraday shield. 
TABLE 1. Comparison of 4-strap circuit parameters calculated from ARGUS results and from 2-D Laplace analyses (septa at $19.5 \mathrm{~cm}$ )

\begin{tabular}{|c|c|c|c|c|c|c|}
\hline Analysis & Strap & $\mathrm{L}_{0}(\mathrm{H} / \mathrm{m})$ & $\mathrm{C}_{0^{\prime}}(\mathrm{F} / \mathrm{m})$ & $\mathrm{Z}_{0}(\Omega)$ & $\mathrm{V}_{\mathbf{p h}} / \mathbf{c}$ & $\mathbf{k}(\%)$ \\
\hline ARGUS & Outer & $2.57 \times 10^{-7}$ & $1.250 \times 10^{-10}$ & 45.3 & 0.588 & $\mathrm{k}_{12}=14.3$ \\
& Inner & $2.78 \times 10^{-7}$ & $1.237 \times 10^{-10}$ & 47.4 & 0.569 & $\mathrm{k}_{23}=14.6$ \\
\hline 2-D Laplace & Outer & $2.56 \times 10^{-7}$ & $1.281 \times 10^{-10}$ & 44.7 & 0.582 & $\mathrm{k}_{12}=13.8$ \\
& Inner & $2.72 \times 10^{-7}$ & $1.281 \times 10^{-10}$ & 46.1 & 0.565 & $\mathrm{k}_{23}=14.4$ \\
\hline
\end{tabular}

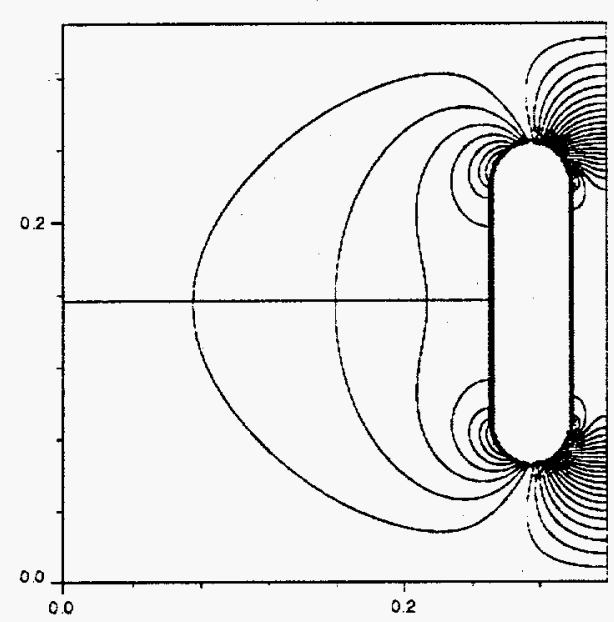

Fig. 2. Contours of constant $\left|E_{\perp}\right|$.

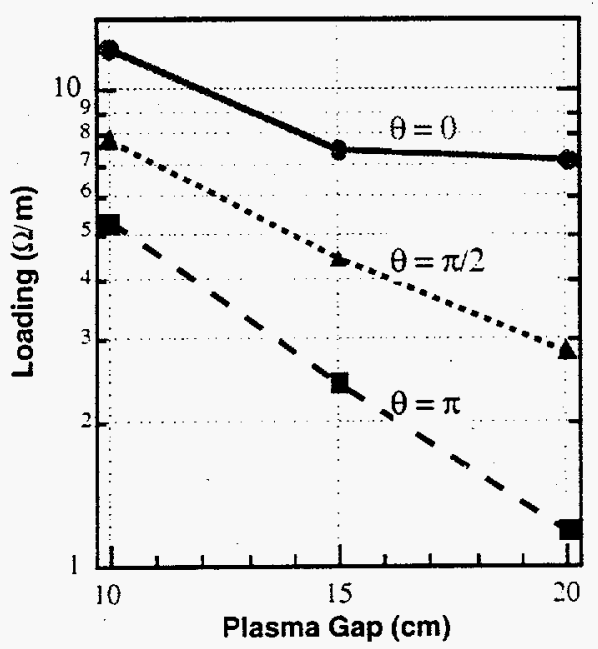

Fig. 4. Plasma loading vs plasma gap (first wall to separatrix) as function of array phase angle for $60 \mathrm{MHz}$. Straps are $18 \mathrm{~cm}$ wide, and septa are at $11 \mathrm{~cm}$.

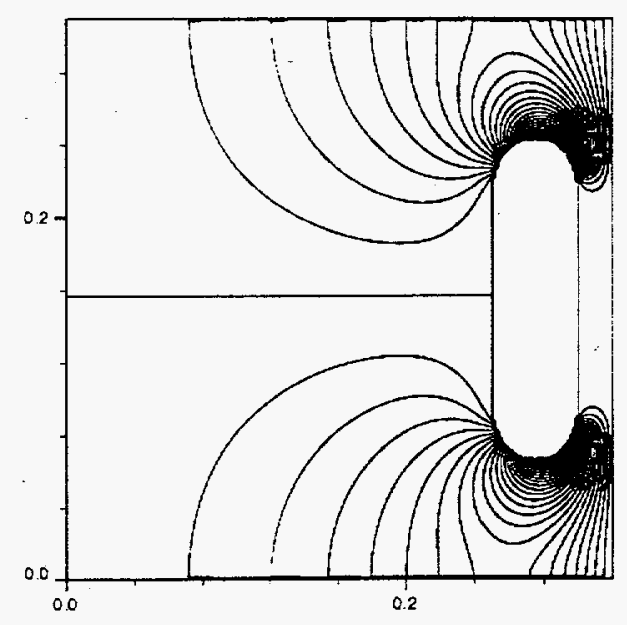

Fig. 3. Contours of constant $\left|E_{\|}\right|$.

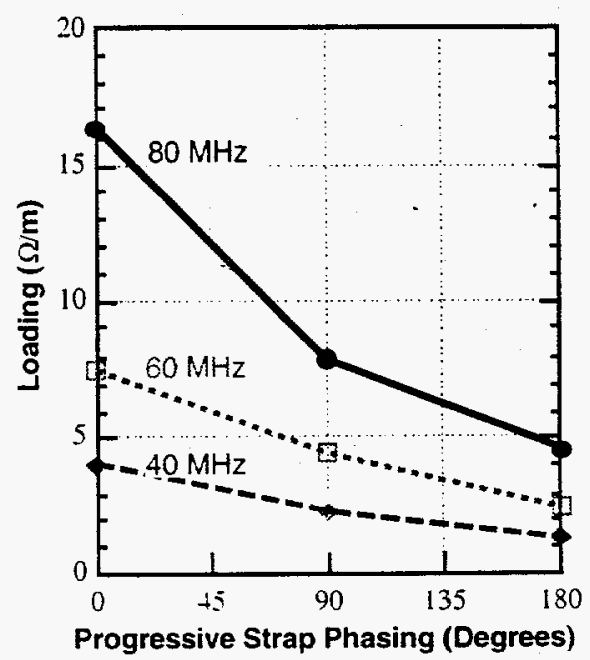

Fig. 5. Plasma loading vs array phase angle as function of frequency. Strap width is $18 \mathrm{~cm}$, and septa are $11 \mathrm{~cm}$ from first wall. 


\section{CONCLUSIONS}

For a fixed power delivered to the plasma, the outcome of the optimization exercise can be summarized as follows:

- Wide straps decrease the peak voltages and electric fields on the strap ends.

- Thick straps $(5 \mathrm{~cm})$ have lower peak voltages and electric fields than thin straps $(4 \mathrm{~cm})$.

- Septum position has negligible effect on peak fields for given power.

- Peak fields increase as the phase angle between adjacent straps increases.

- Peak fields as a function of frequency are slightly higher at $60 \mathrm{MHz}$ than at 40 or $80 \mathrm{MHz}$.

Fig 6. shows the decrease in peak voltage on the strap as the width is increased for full power $60 \mathrm{MHz}$ operation. For frequencies below $80 \mathrm{MHz}$, the peak voltages occur in the feeder/stub tuner section, as shown in Fig. 7 for a $22 \mathrm{~cm}$ wide by 5 $\mathrm{cm}$ thick strap. Such a strap has $\mathrm{Z}_{0}=38.3 \Omega$, a phase velocity of $0.65 c$, and mutual coupling coefficient of $6.1 \%$. The maximum $E_{\|}$is $37.8 \mathrm{~V} / \mathrm{m}$ (normalized to a peak strap voltage of $1 \mathrm{~V}$ ). The ratio of $E_{\perp}$ to $E_{\boldsymbol{l}}$ is 1.5 .

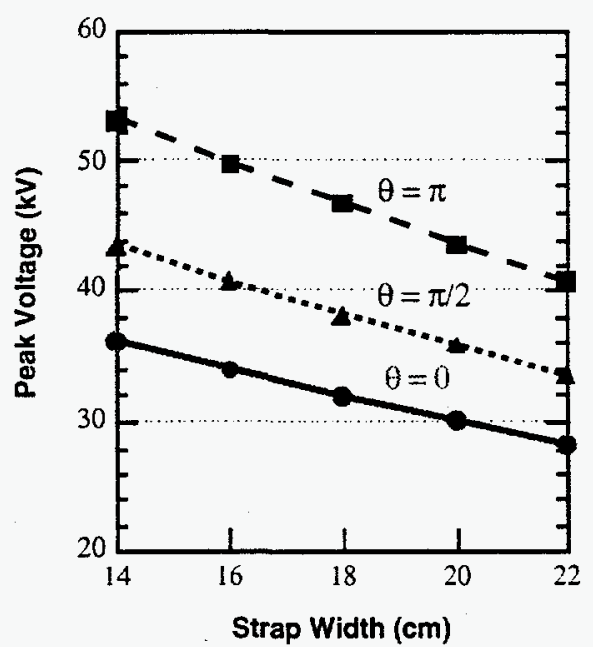

Fig. 6. Peak voltage on current strap vs strap width as function of relative phasing for $60-\mathrm{MHz}$ operation. Power is $12.5 \mathrm{MW}$ per port; plasma gap is $15 \mathrm{~cm}$.

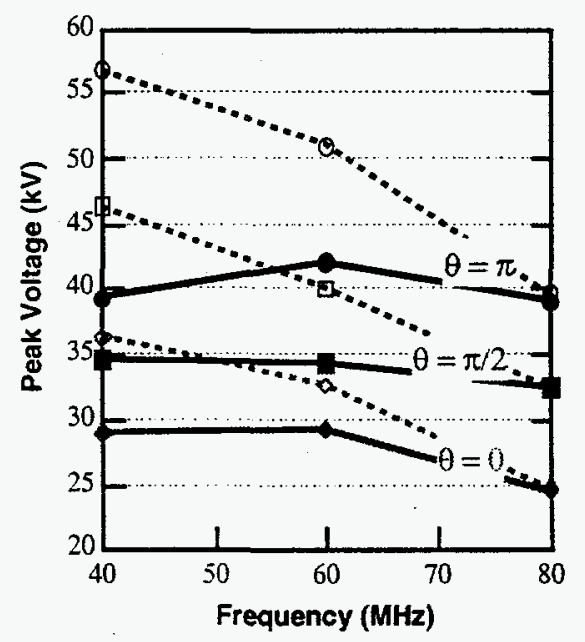

Fig. 7. $V_{\max }$ vs $f$ as function of $\theta$. Solid curves are on strap; dashed curves are on RDL. Straps are $22 \mathrm{~cm}$ wide and $5 \mathrm{~cm}$ thick; septum at $10.5 \mathrm{~cm}$. Feeder and stub tuner impedances are 50 and $20 \Omega$

\section{REFERENCES}

[1] G. Bosia, "Status of ITER Antenna/VTL Design", 15th Mtg. of the Co-ordinating Committee on Fast Wave Current Drive and Heating and Joint ITER Working Meeting (D320, T235-8), Garching, Germany, 21-24 May 1996.

[2] Ryan, P. M.. et al, Fusion Engrg. Des. 24 (1994) 135

[3] Ho, Y. L., Grossman. W., Drobot. A.. Carter, M. D., Ryan, P. M.. Batchelor, D. B., 10th Top. Conf. on RF Power in Plasmas, AIP Conf. Proc. 289 (Boston, MA. 1993) 359

[4] Carter. M. D., et al, Nucl. Fusion 36 ( 1996) 209 


\section{DISCLAIMER}

This report was prepared as an account of work sponsored by an agency of the United States Government. Neither the United States Government nor any agency thereof, nor any of their employees, makes any warranty, express or implied, or . assumes any legal liability or responsibility for the accuracy, completeness, or usefulness of any information, apparatus, product, or process disclosed, or represents that its use would not infringe privately owned rights. Reference herein to any specific commercial product, process, or service by trade name, trademark, manufacturer, or otherwise does not necessarily constitute or imply its endorsement, recommendation, or favoring by the United States Government or any agency thereof. The views and opinions of authors expressed herein do not necessarily state or reflect those of the United States Government or any agency thereof. 


\section{DISCLAMIER}

Portions of this document may be illegible in electronic image products. Images are produced from the best available original document. 